\title{
Influence of controlled deposition rate on mechanical properties of sputtered Ti thin films for MEMS application
}

\author{
S. VENKATESAN ${ }^{1, *}$, M. RAMU ${ }^{2}$ \\ ${ }^{1}$ Department of Mechanical Engineering, N.G.P. Institute of Technology, Coimbatore-641048, Tamil Nadu, India \\ ${ }^{2}$ Department of Mechanical Engineering, PSG College of Technology, Coimbatore-641004, Tamil Nadu, India
}

\begin{abstract}
This work investigates the influence of titanium thin films on the mechanical properties of AA 2024 substrates. The Scanning Electron Microscope (SEM) measurements confirm that the surface morphology of Ti thin film depends on controlled deposition rate and the energy-dispersive X-ray (EDX) result reveals the uniform dispersion of Ti coating over the sample. Increase in film thickness on the material surface is connected with improved hardness, superior adhesion and minimum surface roughness which makes the coated material more prominent for MEMS application. It is also found that the XRD patterns of the Ti thin films are characterized by hexagonal close packed (HCP) structure with $\left(\begin{array}{lll}1 & 1 & 1\end{array}\right)$ as the preferred crystallographic orientation for the film of a thickness of $154 \mu \mathrm{m}$ coated on the substrate at temperature of $673 \mathrm{~K}$.
\end{abstract}

Keywords: titanium; thin films; sputtering; hardness; MEMS

(C) Wroclaw University of Technology.

\section{Introduction}

Titanium thin films have been widely used in different areas of semiconductor device technology because of their desirable mechanical properties, such as high hardness, good corrosion and wear resistance, metallurgical stability and seem to be the best replacement of polycrystalline Si in very large-scale integrated circuits [1-4]. For the development of new materials in MEMS application, in addition to their mechanical characteristics including high hardness and good elasticity, fine adhesion and low interface stresses may play an important role in long-term reliability problems [1]. Among different methods of titanium thin film preparation, including physical vapor deposition, plasma focus, chemical vapor deposition, electrochemical and chemical nitriding, sputtering, and ion implantation [1, 5-17], direct-current (DC) magnetron sputtering is a simple and most appropriate method. However, the mechanical properties and crystallographic structure of titanium thin film in this method

*E-mail: vnsvenkatesan@gmail.com are strongly dependent on process parameters such as sputtering power, substrate temperature and sputtering pressure. The aim of this work is to investigate the influence of controlled deposition rate on the surface morphology and mechanical properties, such as hardness, scratch resistance, adhesion, surface roughness and crystallographic structure of sputtered titanium thin films. The results of this study can be used in MEMS applications as stated throughout this section.

\section{Experimental}

\subsection{Film preparation}

Titanium thin films were deposited using a DC reactive magnetron sputtering system with a circular $50.8 \mathrm{~mm}$ in diameter $\mathrm{Ti}$ target of $99.99 \%$ purity. The target-to-substrate distance was $100 \mathrm{~mm}$. A continually variable DC power supply of $4 \times 10^{4} \mathrm{~W} / \mathrm{m}^{2}$ was used as the power source for sputtering. The thickness and deposition rate of the titanium nitride films were checked in situ using a quartz crystal monitor (Vacutech System, Bangalore) located near the substrate during 
the sputtering process. The substrates, $30 \times 30 \mathrm{~mm}^{2}$ perfect square shape AA 2024 samples, were ultrasonically cleaned in heated acetone then etalon. The base pressure was maintained at $0.15 \mathrm{~Pa}$. Pure argon gas (99.99\% purity) and nitrogen gas (99.99\% purity) were used as sputter and reactive gases, respectively. Titanium thin films were deposited under the controlled flow rates of both argon and nitrogen gases individually, using mass flow controllers. The titanium was deposited on AA 2024 samples S1, S2, S3 and S4 at substrate temperature form $373 \mathrm{~K}$ to $673 \mathrm{~K}$ at different deposition times of $180 \mathrm{~s}, 300 \mathrm{~s}, 420 \mathrm{~s}$ and $900 \mathrm{~s}$.

\subsection{Film characterization}

Metallurgical microscope (Metscope 1A) with a magnification factor of $\times 100$ was used to attain the cross-sectional image of Ti thin film. The surface morphology of Ti film was studied by scanning electron microscope (SEM, Zeiss EB018). The energy-dispersive X-ray (EDX) spectrometer was used to find the chemical composition of the coated samples. The pure Ti thin films were characterized using an X-ray diffractometer (XRD, Panalytical) with a scan rate of $1^{\circ} \mathrm{min}^{-1}$ and scan range of $2 \theta$ degree angle between $10^{\circ}$ and $80^{\circ}$. The hardness of the Ti thin film was evaluated using Vickers microhardness tester (Qness Q10A). Scratch test and adhesion measurements were done on the samples at room temperature. Finally the surface roughness values were measured using a surface roughness tester (Rugosurf 10G).

\section{Results and discussion}

\subsection{Surface morphology and EDX}

Metallurgical microscope (Metscope 1A) with a magnification factor of $\times 100$ has been used to attain the cross-sectional images of Ti thin film. According to the standard ASM (Handbook Volume 9), the Ti film thickness was found to be $45 \mu \mathrm{m}, 60 \mu \mathrm{m}$, $86 \mu \mathrm{m}$ and $153 \mu \mathrm{m}$ (Table 1) for samples S1, S2, S3 and S4, respectively as shown in Fig. 1.

The surface morphology of Ti films was studied by scanning electron microscope (SEM, ZEISS EB018). Cross-sectional images of the films are

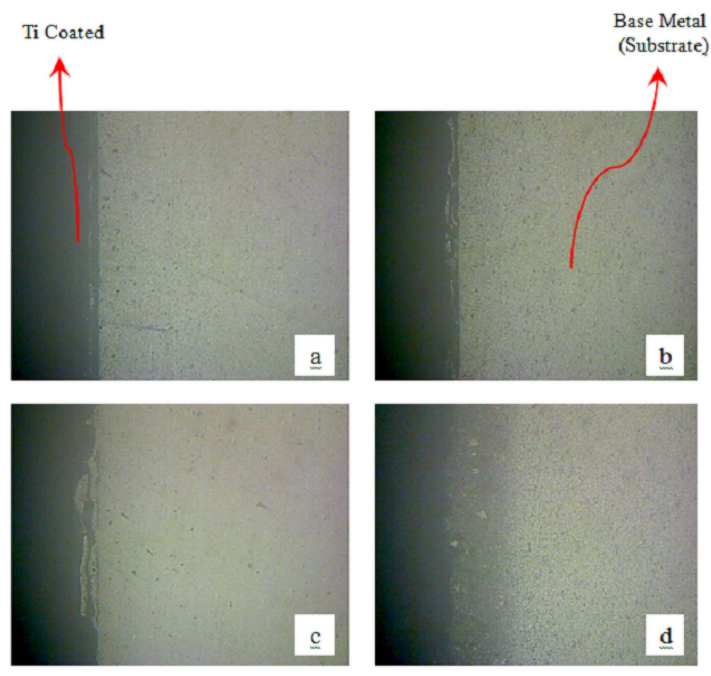

Fig. 1. Cross-sectional images of film thickness: (a) $45 \mu \mathrm{m}$, (b) $61 \mu \mathrm{m}$, (c) $82 \mu \mathrm{m}$, and (d) $154 \mu \mathrm{m}$ of AA 2024 samples obtained at different deposition times.

shown in Fig. 2. Uniform distribution of Ti films is a prerequisite to improve the mechanical properties of the AA 2024 substrate. With an increase in deposition time, the density of the Ti film has increased with lesser fraction of voids due to the higher adatoms mobility.
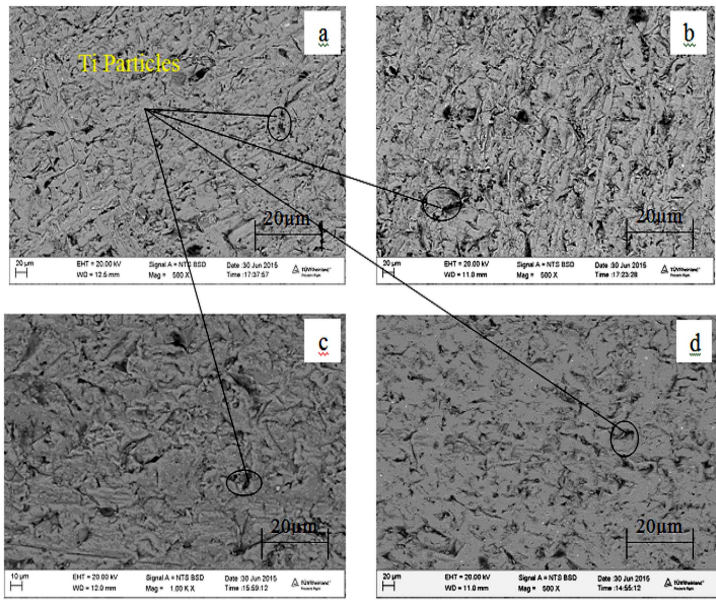

Fig. 2. SEM images of AA 2024 substrates coated with Ti thin films at different deposition times: (a) $180 \mathrm{~s}$, (b) $300 \mathrm{~s}$, (c) $420 \mathrm{~s}$, and (d) $900 \mathrm{~s}$.

It is evident that the morphology of the grains changes and becomes denser due to the higher 
Table 1. Film thickness of samples S0, S1, S2, S3 and S4 for different deposition times and temperatures.

\begin{tabular}{cccc}
\hline Sample & Deposition time $[\mathrm{s}]$ & Temperature $[\mathrm{K}]$ & Film thickness $[\mu \mathrm{m}]$ \\
\hline \hline S0 (uncoated sample) & - & - & - \\
S1 & 180 & 373 & 45 \\
S2 & 300 & 473 & 60 \\
S3 & 420 & 573 & 86 \\
S4 & 900 & 673 & 153 \\
\hline
\end{tabular}
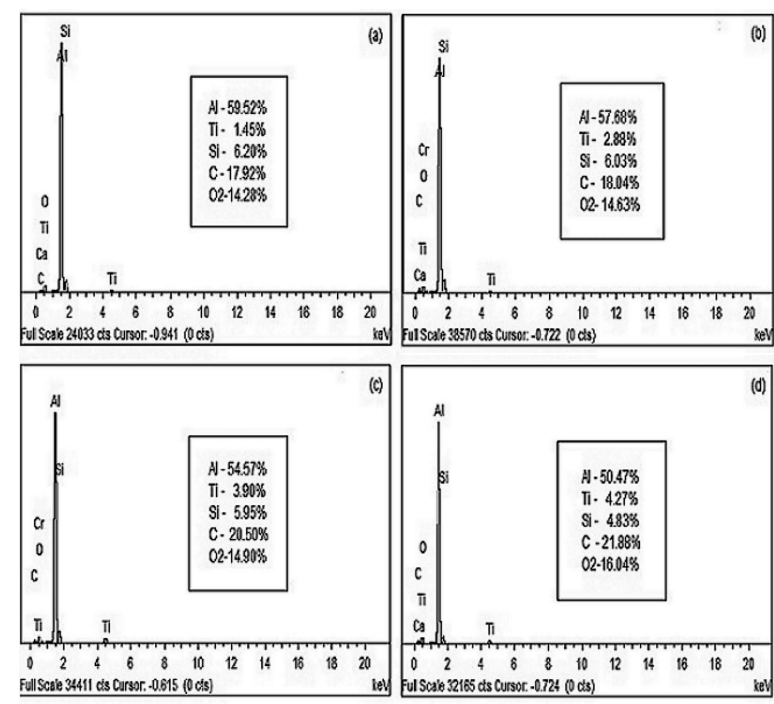

Fig. 3. EDX analysis of AA 2024 sample coated by Ti thin films at different deposition times: (a) $180 \mathrm{~s}$, (b) $300 \mathrm{~s}$, (c) $420 \mathrm{~s}$, and (d) $900 \mathrm{~s}$.

surface and bulk diffusivity of sputtered atoms. In the EDX analysis the chemical composition of $\mathrm{Al}$, Ti, Si, C and $\mathrm{O}_{2}$ on Ti coated AA 2024 substrate was studied by energy-dispersive X-ray (EDX) spectrometer as shown in Fig. 3. The Ti films sputtered at different deposition times have aluminium (Al) content decreasing from $59.52 \%$ to $50.47 \%$ by weight, titanium (Ti) content increasing from $1.45 \%$ to $4.27 \%$ by weight, silicon $(\mathrm{Si})$ content decreasing from $6.20 \%$ to $4.83 \%$ by weight. Finally the content of carbon increases from $17.92 \%$ to $21.88 \%$ by weight and the content of oxygen also increases from $14.28 \%$ to $16.04 \%$ by weight.

\subsection{Mechanical properties}

Fig. 4 illustrates the variation of hardness of all Ti/AA2024 thin films as a function of Ti film thickness. As can be seen, an increase in the deposition time and substrate temperature cause an increase of this quantity. The hardness and mechanical properties of films can be affected by different parameters such as grain size, crystallographic orientations, film density, lattice parameters, and stoichiometry $[1,10,12,18]$. Although the variation of grain size with the deposition time is not large, the increase of hardness can be attributed to (i) film growth (ii) the increase of density or elimination of voids, (iii) improvement of crystal quality with increasing deposition time. The measurements were carried out at ten different places in each sample S0, S1, S2, S3 and S4 with the applied load of $2 \mathrm{~N}$ for 10 seconds dwell time by the test method (IS $1501: 2002)$ at ambient temperature of $298 \mathrm{~K}$ and the average value was taken. The coatings exhibit the hardness value of $84.3 \mathrm{HV}$ for the sample S4 with film thickness of $153 \mu \mathrm{m}$, which is higher than the value of $55 \mathrm{HV}$ for the uncoated sample S0. It is observed that the hardness of Ti coated AA 2024 substrates increases with the increase in film thickness, deposition time and substrate temperature.

\subsection{Evaluation of scratch resistance, ad- hesion and surface roughness}

The loads of $0.20 \mathrm{~N}, 0.50 \mathrm{~N}, 1 \mathrm{~N}, 2 \mathrm{~N}, 3 \mathrm{~N}$, $4 \mathrm{~N}, 5 \mathrm{~N}$ and $6 \mathrm{~N}$ with test reference IS 101 (Part 5/Sect. 2) have been applied using scratch test apparatus to observe the scratch mark on the coated samples S0, S1, S2, S3 and S4, respectively as shown in Fig. 5.

Fig. 6 shows that with the increase in film thickness, the scratch noticed on Ti coated sample S4 with applied load of $6 \mathrm{~N}$ is higher than on the uncoated sample $\mathrm{S} 0$ at $1 \mathrm{~N}$. The adhesion test (cross hatch test) performed on titanium coated AA 2024 


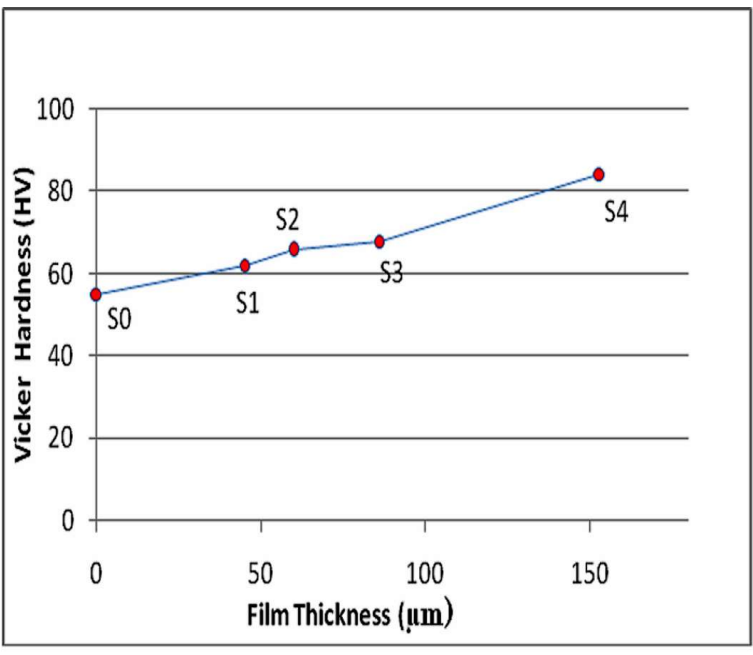

Fig. 4. Effect of film thickness on hardness.

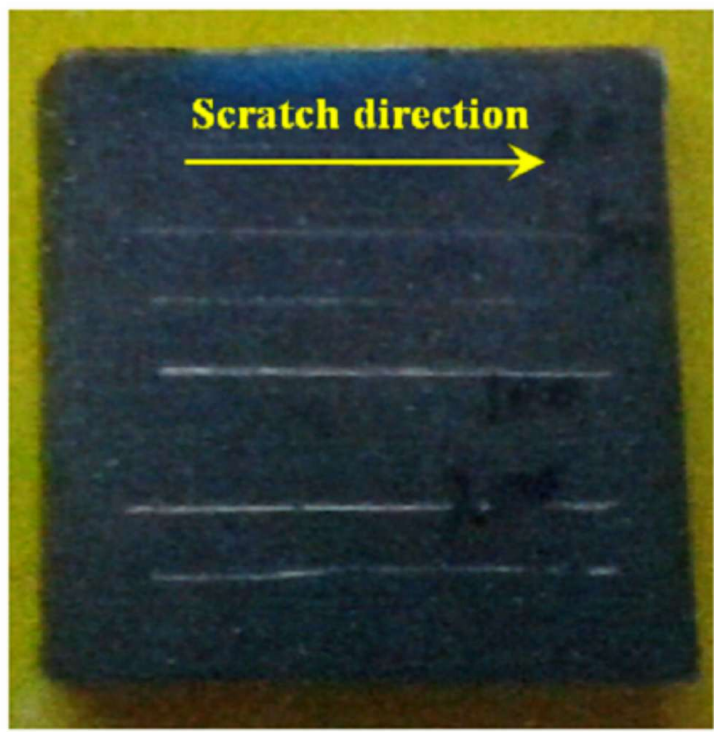

Fig. 5. Scratches on titanium coated AA 2024 samples.

samples showed that the edges of the cuts were entirely smooth.

A lattice pattern with six lines in each direction was made on the film on the substrate as shown in the Fig. 7 and a pressure sensitive tape was applied over the pattern and then removed. The adhesion of the coated samples was evaluated and the result showed that all the sample passed the test with grade $5 \mathrm{~B}$ and none of the squares of the lattice was detached as per ASTM D3359-09 standards.

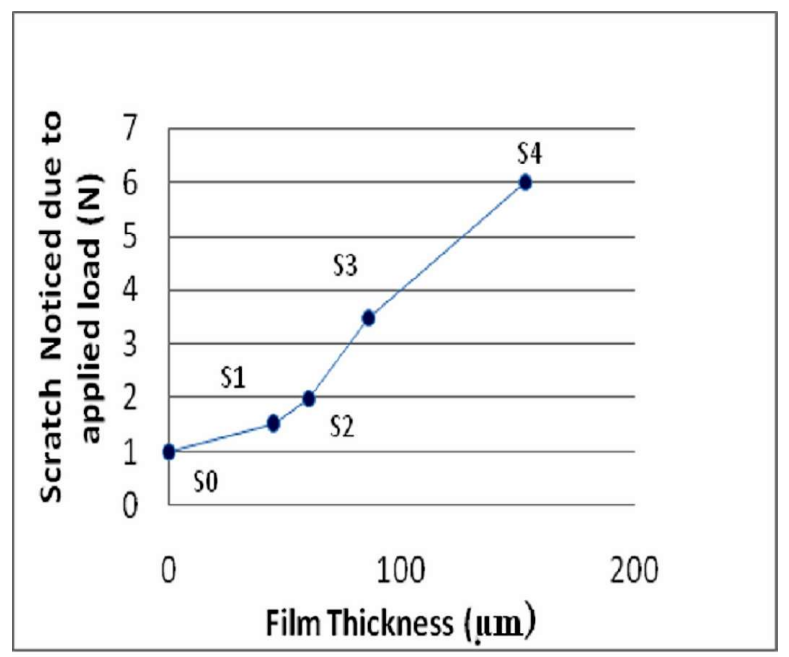

Fig. 6. Effect of film thickness on scratch caused by the applied load (N).

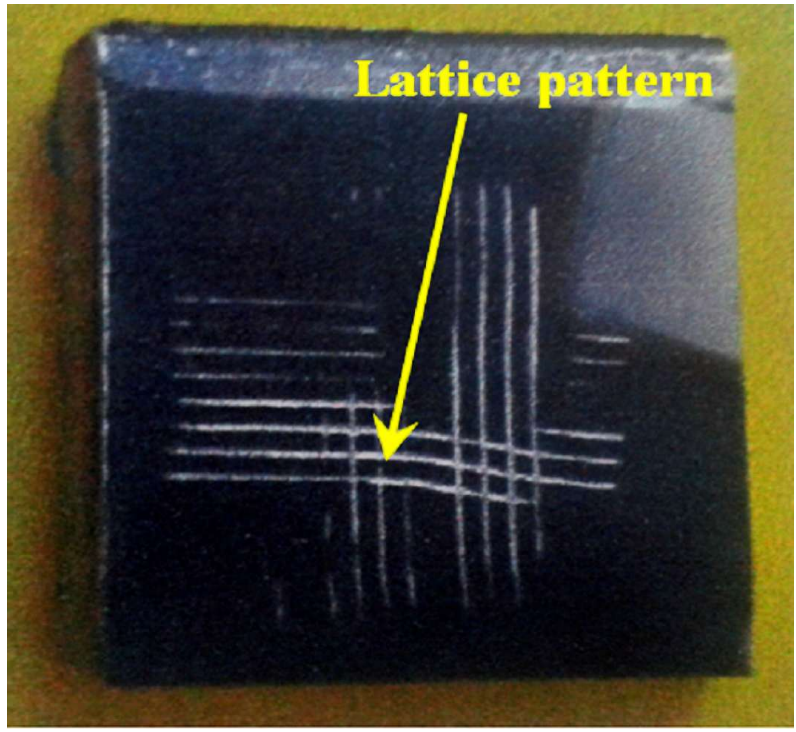

Fig. 7. A lattice pattern with six lines in each direction made on titanium coated AA 2024 sample (cross hatch test).

Fig. 8 clearly reveals that with an increase in film thickness, the surface roughness value of titanium film deposited on AA 2024 samples S1, S2, S3 and S4 decreased from $1.17 \mu \mathrm{m}$ to $0.92 \mu \mathrm{m}$ compared to uncoated sample S0 whose roughness was $1.55 \mu \mathrm{m}$. The lower surface roughness value led to higher thin film adhesion and scratch resistance. 


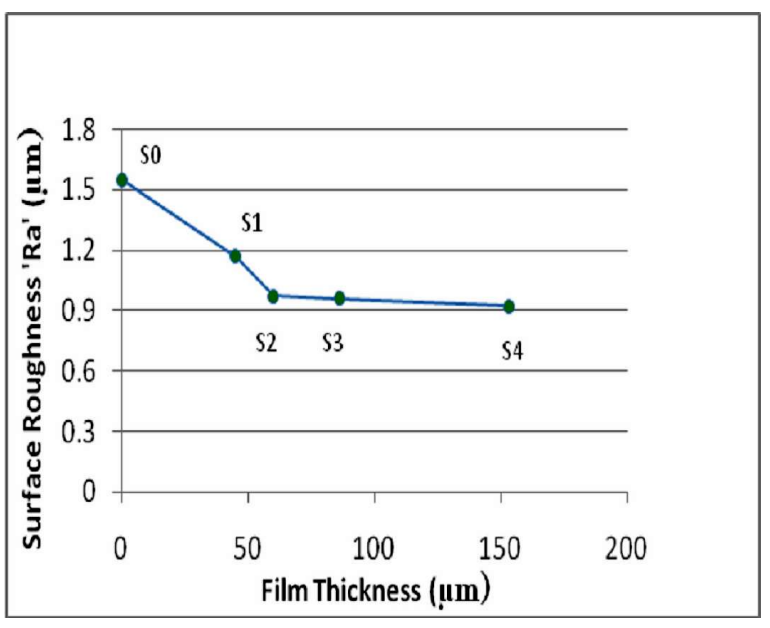

Fig. 8. Effect of film thickness on surface roughness.

\subsection{Crystallographic structure}

It is shown in Fig. 9 that the XRD pattern of the deposited Ti film on AA 2024 sample S4 for deposition time of $900 \mathrm{~s}$ at substrate temperature of $673 \mathrm{~K}$ has two peaks at $38^{\circ}$ and $44^{\circ}$ that can

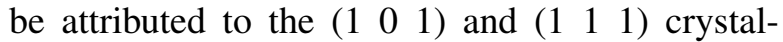
lographic planes of $\mathrm{Ti}$ with a face-centered cubic (FCC) structure. It was observed that initially the $\mathrm{Ti}$ film exhibited (llll 010 ) preferred orientation but with increasing temperature ( $\left.\begin{array}{lll}1 & 1 & 1\end{array}\right)$ became the preferred orientation. The higher substrate temperature could facilitate the enhanced mobility of atoms on the film surface and favor the formation of (lllll) orientated grains. It is evident that the $\left(\begin{array}{lll}1 & 0 & 1\end{array}\right)$ peak transformed into (1 111 ) preferred plane. It is known that $\mathrm{Ti}$ films deposited by various physical vapor deposition methods generally grow in three crystallographic orientations (i.e. (2 $\left.\begin{array}{lll}2 & 0\end{array}\right),\left(\begin{array}{lll}1 & 1 & 1\end{array}\right)$ and (2 2 (2) 0 ) [19]. The preferred orientation of a film results from its lowest overall energy, which is a result of competition between the surface energy, the strain energy, and the stopping energy of different lattice planes [20,21]. In the case of Ti films, the $\left(\begin{array}{ll}2 & 0\end{array}\right)$ plane has the lowest surface energy, the (1 11 1) plane has the lowest strain energy, and the (2 1 5) plane has the lowest stopping energy. Only when the deposited ion energy is sufficiently high, the stopping energy becomes dominant, and the preferred (2 115 ) orientation can be observed [19]. Hence, one may propose that only surface energy and strain energy have affected the film growth process. Crystallite size (coherently diffracting domains) $\mathrm{D}$ was obtained by applying the Scherrer formula $(D=k \lambda / B \cos \theta)$ to measure the full width at half maximum (FWHM) of the dominant peak $\mathrm{Ti}\left(\begin{array}{lll}1 & 0 & 1\end{array}\right)$ in the XRD patterns [22], where $\mathrm{k}=0.9$, $\lambda=1.54248 \AA, \mathrm{B}=\mathrm{FWHM}$ that is calculated from $\mathrm{B}^{2}=\mathrm{B}_{M}^{2}-\mathrm{B}_{\mathrm{S}}^{2}\left(\mathrm{~B}_{\mathrm{M}}, \mathrm{FWHM}\right.$ of the sample and $\mathrm{B}_{S}$, FWHM of the standard sample), and $\theta$ is the peak position in radian. The crystallite size of $3579 \AA$ at the deposition time of $900 \mathrm{~s}$ and substrate temperature of $673 \mathrm{~K}$ can be attributed to the enhanced energetic ion bombardment and promoted mobility of adatoms. When the deposition and substrate temperature increases, the ion density becomes large enough for crystal growth [19, 23].

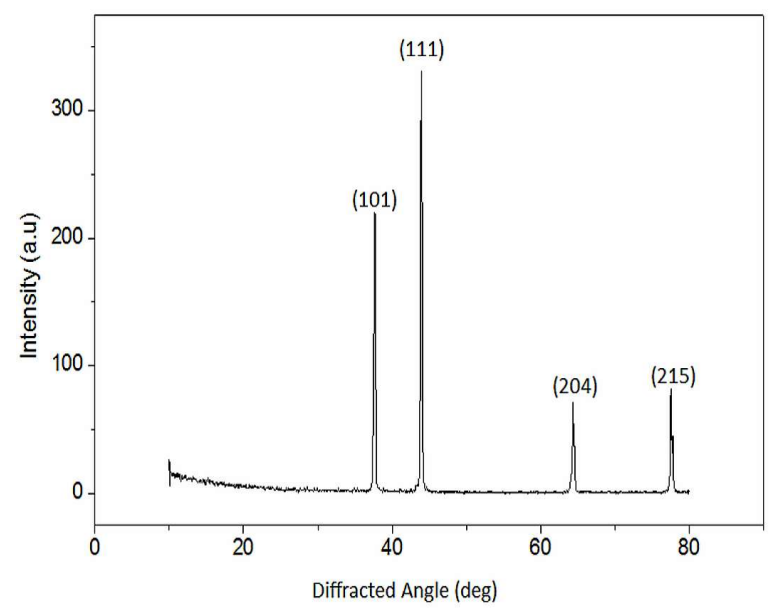

Fig. 9. XRD pattern of Ti film deposited on AA 2024, sample S4 obtained at deposition time of $900 \mathrm{~s}$ at substrate temperature of $673 \mathrm{~K}$.

\section{Conclusions}

This work discusses the results of investigation carried out on metallic titanium film deposited on AA 2024 substrate using DC magnetron sputtering method at different deposition times and substrate temperatures. The following conclusions have been obtained in the present investigation:

- Structural investigation showed that Ti thin films had a FCC structure for all samples.

- The surface morphology of the samples showed a granular structure with 
small grains, and the grain size increased consistently as a result of energetic ion bombardment.

- The mechanical studies showed that the film surface hardness increased significantly from $55 \mathrm{HV}$ to $84.3 \mathrm{HV}$ due to the increase in film thickness.

- Scratch resistance, adhesion behavior and surface roughness of the film were consistent with similar works which is a sign of the progress in thin film sputtering deposition, predominantly for the fabrication of microminiaturized MEMS devices.

- It was also observed that (lllll 111 crystallographic orientation was the preferred orientation for Ti thin film grown for $900 \mathrm{~s}$ at substrate temperature of $673 \mathrm{~K}$.

- The results of hardness and scratch resistance test performed on the Ti coated AA 2024 sample confirmed that the alloy is suitable for microminiaturized MEMS device applications.

\section{Acknowledgements}

The authors would like to thank the support provided by the Department of Physics, Karunya University (Coimbatore, India), TUV Rheinland (India) Pvt. Ltd.,(Bangalore, India), Omega Inspection \& Analytical Laboratory (Chennai, India), Department of Nanotechnology, Sri Ramakrishna Engineering College, (Coimbatore, India) and Tespa Calibration Center (Coimbatore, India).

\section{References}

[1] Patsalas P., Charitidis C., Logothetidis S., Surf. Coat. Technol., 125 (2000), 335.

[2] Travis E.Q., Fiordalice R.F., Solid Films, 236 (1993), 325.

[3] Gagnon G., Currie J.F., Beique C., Brebner J.L., Gujrathi S.G., Onlett L., J. Appl. Phys., 75 (1994), 1565.

[4] Hara T., Yamanoue A., Iio H., Inoue K., Washidzu G., Nakamura S., Jpn. J. Appl. Phys., 30 (1991), 1447.
[5] Vaz F., Ferreira J., Ribeiro E., Rebouta L., Lanceros-Mendez S., Mendez J.A., Alves E., GoudeAu P., Riviere J.P., RibeIRo F., Moutinho I., Pischow K., RiJk J., Surf. Coat. Technol., 191 (2005), 317.

[6] ERIKSSON L., Harju E., Korhonen A.S., PISCHOw K., Surf. Coat. Technol., 53 (1992), 153.

[7] Chou W.J., Yu G.P., Huang J.H., Surf. Coat. Technol., 149 (2002), 7.

[8] Valvoda V., J. Alloy. Compd., 219 (1995), 83.

[9] Baker M.A., Monclus M.A., Rebholz C., GibSon P.N., LeYland A., Matthews A., Thin Solid Films, 518, (2010), 4273.

[10] Hainsworth S.V., SoH W.C., Surf. Coat. Technol., 163 - 164 (2003), 515.

[11] Kumar A., Singh D., Kumar R., Kaura D., J. Alloy. Compd., 479 (2009), 166.

[12] Holleck H., J. Vac. Sci. Technol. A, 4 (2661) (1986), 2661.

[13] Savaloni H., Khojier K., Torabi S., Corros. Sci., 52 (2010), 1263.

[14] Chatterjee S., Chandrashekhar S., SudarSHAN T.S., J. Mater. Sci., 27 (1992), 3409.

[15] Russell S.W., RACK M.J., Adams D., Alford T.L., J. Electrochem. Soc., 143 (1996), 2349.

[16] Firouzi M., Savaloni H., Ghoronneviss M., Appl. Surf. Sci., 256 (2010), 4502.

[17] Fani N., Savaloni H., J. Theor. Appl. Phys., 6 (2012), 1.

[18] Wang T.G., Jeong D., LiU Y., Wang Q., IYenGAR S., Melin S., Kim K.H., Surf. Coat. Technol., 206 (2012), 2638.

[19] Arshi N., Lu J., Joo Y.K., LeE C.G., Yoon J.H., Ahmed F., Mater. Chem. Phys., 134 (2012), 839.

[20] Zhao J.P., Wang X., Chen Z.Y., Yang S.Q., Shi T.S., LIU X.H., J. Phys. D-Appl. Phys., 30 (1997), 5.

[21] Pellegeg J., Zevin LZ., Lungo S., Thin Solid Films, 197 (1991), 117.

[22] Warren B.E., X-ray Diffraction, Addison-Wesley, London, 1969.

[23] Yu G.Q., Tay B.K., Lau S.P., Prasad K., Pan L.K., Chai J.W., LaI D., Chem. Phys. Lett., 374 (2003), 264. 